\title{
Assessment of Agricultural Sector Policies and Climate Change in Malawi-The Nexus between Climate Change Related Policies, Research and Practice
}

\author{
Weston Mwase ${ }^{1}$, C. B. L. Jumbe ${ }^{1}$, F. Gasc ${ }^{2}$, T. Owiyo ${ }^{2}$, D. Manduwa ${ }^{1}$, J. Nyaika $^{1}$, K. Kwapata ${ }^{1} \&$ B. Maonga ${ }^{1}$ \\ ${ }^{1}$ Lilongwe University of Agriculture and Natural Resources, Bunda Campus, Lilongwe, Malawi \\ ${ }^{2}$ African Climate Policy Centre, UN Economic Commission for Africa, Addis Ababa, Ethiopia \\ Correspondence: Weston Mwase, Department of Forestry, Lilongwe University of Agriculture and Natural \\ Resources, Bunda Campus, P.O Box 219, Lilongwe, Malawi. Tel: 26-5127-7260. E-mail: \\ westmwase@yahoo.co.uk
}

\author{
Received: March 4, 2014 Accepted: October 21, $2014 \quad$ Online Published: November 26, 2014 \\ doi:10.5539/jsd.v7n6p195 URL: http://dx.doi.org/10.5539/jsd.v7n6p195
}

\begin{abstract}
This paper presents results of the assessment of major agricultural related policies in relationship to climate change issues conducted in Malawi to determine the extent to which agricultural sector policy integrates with climate related issues to influence practice and research. Over thirty government policies related to agriculture were reviewed and 50 key informants from government, non-governmental organizations and agricultural research institutes were interviewed. Results revealed that research does not sufficiently influence and inform policy and practice because implementation is greatly influenced by politics and relationship with development partners; only $20 \%$ of independent agricultural research outputs find its way into policy and practice while $24 \%$ of research by civil society gets absorbed into policy. Collaborative research among government, civil society and academia results in $41 \%$ of research output informing policy and practice. Development partners and civil society organizations have more influence in policy formulation and practice through campaign and advocacy. Climate Change policy for Malawi was still in draft form and the absence of policy has led to duplication of efforts by stakeholders in implementing climate change projects. Weak links between researchers, policy makers, and donor partners are some of the challenges that limit contribution of agricultural research to inform policy and practice. This study calls for harmonization of all outdated agricultural sector policies and mainstream them into climate change framework to influence agricultural practice..
\end{abstract}

Keywords: agricultural research, climate change, mainstreaming policy, practice

\section{Introduction}

The economy of Malawi is primarily dependent on the agricultural sector which accounts for more than $80 \%$ of export earnings, contributing 36\% of gross domestic product (GDP), and providing livelihood for $85 \%$ of the population. Malawi is experiencing increasing climate variability which results in crop failure and poor crop yields due to drought and floods. Malawi depends on rain fed agriculture and this makes the country vulnerable to climate-related shocks culminating into low agricultural production and productivity. For example, Malawi experienced low agricultural production between 2011 and 2013 due to unreliable rainfall patterns, dry spells, droughts and floods, which depressed economic growth and development (Government of Malawi, 2011a). Climate change amongst other challenges has emerged a significant factor in agricultural production in Malawi.

The agricultural sector is guided by a number of policy frameworks. One such a framework is the Agricultural Sector Wide Approach (ASWAP) which was developed with the aim of increasing agricultural productivity, improving food security, diversifying food production to improve nutrition and increase household incomes for rural people. The ASWAP is a priority programmed in the Malawi Growth and Development Strategy (MGDs) and it is tandem with the Comprehensive African Agricultural Development Programmed (CAADP) of the New Partnership for Africa's Development (NEPAD) (Government of Malawi, 2011b). The Aswan identifies three focus areas namely Food Security and Risk Management; Commercial Agriculture, Agro-processing and Market Development and Sustainable Agricultural Land and Water management. The ASWAp operates with the Malawi Growth and Development Strategy II (MGDS II) in the areas of agriculture, food security, water development 
and disaster risk reduction. The MGDS II is the government's overarching medium term strategy (2011-2016) to attain the nation's Vision 2020. The main objective of the MGDS II is to continue reducing poverty through sustainable economic growth and infrastructure development and it places emphasis on six thematic areas namely sustainable economic growth, social development, social support and disaster risk management, infrastructure development, improved governance and cross-cutting issues.

Initiatives in policy formulation and implementation need to observe any challenges and opportunities that result from the impact of climate change and climate variability. Better utilization of research data and evidence in development policy and practice can help in reducing poverty and improve the livelihood of communities. For example, the results of household disease surveys in rural Tanzania informed a process of health service reforms which contributed to over 40 percent reductions in infant mortality between 2000 and 2003 (Court, 2005). Policies in the agricultural and environmental sectors should influence practice on the ground by building resilience against climate change and climate variability through appropriate adaptation strategies such as use of improved and innovative technologies, appropriate land use management practices, timely supply of agricultural inputs, functional farmer associations, and improving access to credit facilities. This study was a collaborative research work between the United Nations Economic Commission for Africa through the African Climate Policy Centre with Lilongwe University of Agriculture and Natural Resources. The objective of the research was to evaluate the extent to which agricultural research addresses aspects of climate change and climate resilience for the agricultural sector and how agricultural research influences policy and practice. The study also assessed the mechansisms that Malawi uses to address climate change issues such as through linking policy, research and practice.

\section{Methodology}

Several approaches were used to collect data on the macro and micro economic aspects of the agricultural sector and the extent to which agricultural research addresses aspects of climate change and climate resilience in Malawi. The data collection methods included desk review of various policy documents, consultation meetings with key stakeholders and in-depth household interviews with selected farmers. A review of secondary data was conducted to get an overview of the role and contribution of agriculture to the economy of Malawi.

\subsection{Consultation Meetings and Study Launch}

A team of researchers from the African Climate Policy Centre and Lilongwe University of Agriculture and Natural resources had consultation meetings with different stakeholders to understand the context in which the exercise would be conducted. A consultative workshop was conducted to which 60 participants from government departments, nongovernmental organisations (NGOs), civil society and farmers' organisations, the academia, and representatives of development partners attended. Participants to the launch identified and prioritized stakeholders for in- depth interviews and refined study tools for data collection. The participants also identified agricultural sector related policies to be reviewed by the researchers.

\subsection{Key Informant Interviews}

Key informant interviews were conducted with relevant stakeholders from Departments of Agricultural Research, Land Resources and Conservation, Economic Planning and Division, Agricultural Extension, Environmental Affairs, Department of Climate Change and Meteorological Services among others. Other stakeholders interviewed included NGOs, Consultative Group for International Agriculture Research (CGIAR), and development partners. The team visited eight key institutions in southern Malawi and twenty institutions in central Malawi. The checklist covered key areas of agricultural research related to climate change; type and source of funding; mode of dissemination of findings; format of dissemination; participating stakeholders; policy formulation strategies; and linkages between agricultural research, policy, and practice.

\subsection{Household Survey}

A total of fifty households were sampled from two villages in Salima district about $150 \mathrm{~km}$ from Lilongwe City to assess how agricultural practice by farmers inform and get influenced by agricultural policy. The National Adaptation Programme of Action (NAPA) for Malawi prioritized five major districts of Balaka, Chikwawa, Karonga, Nsanje and Salima for implementation of climate change adaptation and mitigation strategies. The villages of Ndindi and Mphunga within Salima district in Central Malawi have had a long history of frequent droughts and floods. The team interviewed farmers on different agricultural practices being promoted in relation to climate change, identified promoters of different practices and documented observations on how farmers are adapting to climate change. The team consulted key and relevant stakeholders of the district namely, District Agricultural Development Officers, Irrigation Officer, Agriculture Extension Development Coordinators, sources 
of information on climate change risks management, early warning signals and adaptation, and mitigation practices for agriculture. The team assessed the extent to which climate change research outcomes inform policy and practice.

\subsection{Review of Policies}

Agricultural related policies were reviewed by sixty key informants to determine if they have mainstreamed climate change issues. This led to a review of over thirty national policies in areas of food security, seed, crops, livestock, fisheries, water, irrigation, forestry, energy, land, environment and related development policies. The extent to which climate change issues are mainstreamed in the different agricultural related policies the policies were assessed on a Likert scale of 0 to 5 ( Table 1) depending on coverage of issues of climate change. The respondents were expected to score along a-5-point Likert scale: very strong (5), strong (4), moderate (3), weak (2) and very weak (1) respectively. The responses to the checklist were analyzed by means procedure whereby a score of 3 above indicated a policy that had issues of climate change being mainstreamed.

Table 1. Policy assessment criteria with respect to climate change

\begin{tabular}{lll}
\hline $\begin{array}{l}\text { Score } \\
0-5\end{array}$ & Rating & Description in policy \\
\hline $0-1.9$ & $\begin{array}{l}\text { very } \\
\text { weak }\end{array}$ & $\begin{array}{l}\text { does not state anything about climate change } \\
\text { does not state explicitly issues of climate change but some aspects that relate to climate change } \\
\text { are covered }\end{array}$ \\
weak & $\begin{array}{l}\text { moder } \\
\text { ate }\end{array}$ & $\begin{array}{l}\text { has clearly defined objectives and strategies for implementation of climate change issues but } \\
\text { has clearly defined objectives and strategies on implementation, monitoring and evaluation on } \\
\text { climate change issues but does not state funding mechanisms }\end{array}$ \\
4-4.9 & strong & $\begin{array}{l}\text { very } \\
\text { has clearly defined objectives, strategies on implementation, funding mechanisms, monitoring } \\
\text { and evaluation on climate change }\end{array}$ \\
\hline
\end{tabular}

\section{Results and Discussion}

\subsection{Macroeconomics of the Agricultural Sector}

The agricultural sector remains the prime driver of the Malawian economy, contributing over $80 \%$ to foreign exchange earnings and employing almost $80 \%$ of the country's total workforce. The agricultural sector contributes about $36 \%$ of the gross domestic product (GDP) of which more than $70 \%$ is from the smallholder sub-sector. Apart from agricultural exports, at the time of the study, the other key driver of Malawi's growth was donor aid currently at US\$ 68.6 per capita, which was much higher than the mean of US\$42.1 per capita for Africa (African Development Bank, 2013). In general, this study finds that most agricultural related policies were formulated long before climate change became an issue of importance. It is only recently from 2004 to date that policy documents that include issues directly addressing climate change have been introduced. Insights to the policies of the pre-2004 period shows no deliberate inclusion of climate change strategies, but they still contain sections which are indirectly addressing climate change management.

\subsection{Production Estimates, Weather Variability and Uptake of Farm Input Subsidy Programme}

At household level the average months of food security for rural households from own production is between six and eight months. Malawi witnessed increased food production from 2005 to 2009, which was largely attributed to good weather and the implementation of the agricultural support programmes including the Farm Input Subsidy Programme. The 2009/2010 crop growing season was faced with dry spells in most of the districts that reduced the overall yield. A similar trend was observed in the year 2011/2012. There is a critical link between food security and maize inputs availability and the environmental conditions in addressing poverty in Malawi. It is in recognition of this fact that the Malawi Government put significant emphasis on investment in agriculture as a prerequisite to economic growth. This policy resulted in the successful implementation of the fertilizer subsidy programme. Government support towards the smallholder farmers through the FISP combined with good rains, 
led to significant increases in maize production from 1.2 million metric tons in 2005/06 to 3.4 million metric tons in 2009/10 (Government of Malawi, 2010)

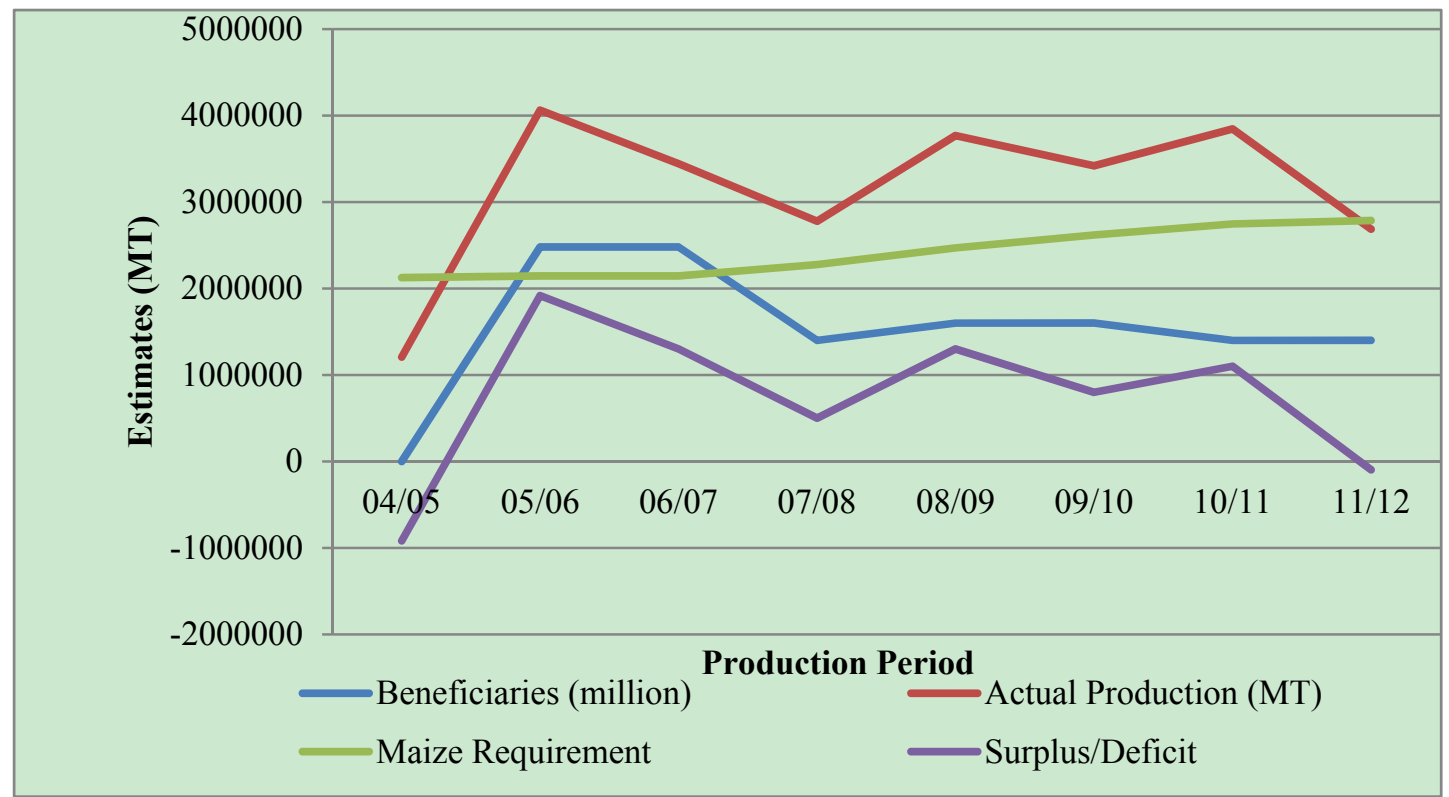

Figure 1. Production estimates of maize from the farm input subsidy programme

Figure 1 shows maize production under the FISP from 2004/05 to 2011/2012. The figure indicates a drop in production in 2004/05 during which time starter packs were provided to limited households, as opposed to the high production from 2005/2006 onwards due to implementation of the farm input subsidy programme. This means that the FISP played a very big role in achieving food security during the period. In addition the higher maize yields were also attributed to favourable weather conditions experienced in the2005/2006 crop growing season.

\subsection{Influence of Agricultural Research on Policy and Practice}

The extent to which agricultural research influences policy depends on several factors, including the nature of the researching organisation, type of research output, and mode of dissemination of the research output. Research outputs to inform policy is mostly produced by government funded National Agricultural Research Centres, Consultative Group for International Agriculture Research, and academic institutions, nongovernmental organisations, and the civil society. The results show that on the average, $22.0 \%$ of the independent research by academic institutions, international agricultural research centres would inform policy while there is $41 \%$ chance that research outputs from collaborative research work among government officials, civil society organization, and agricultural researchers would inform agricultural policy and practice (Figure 2). 


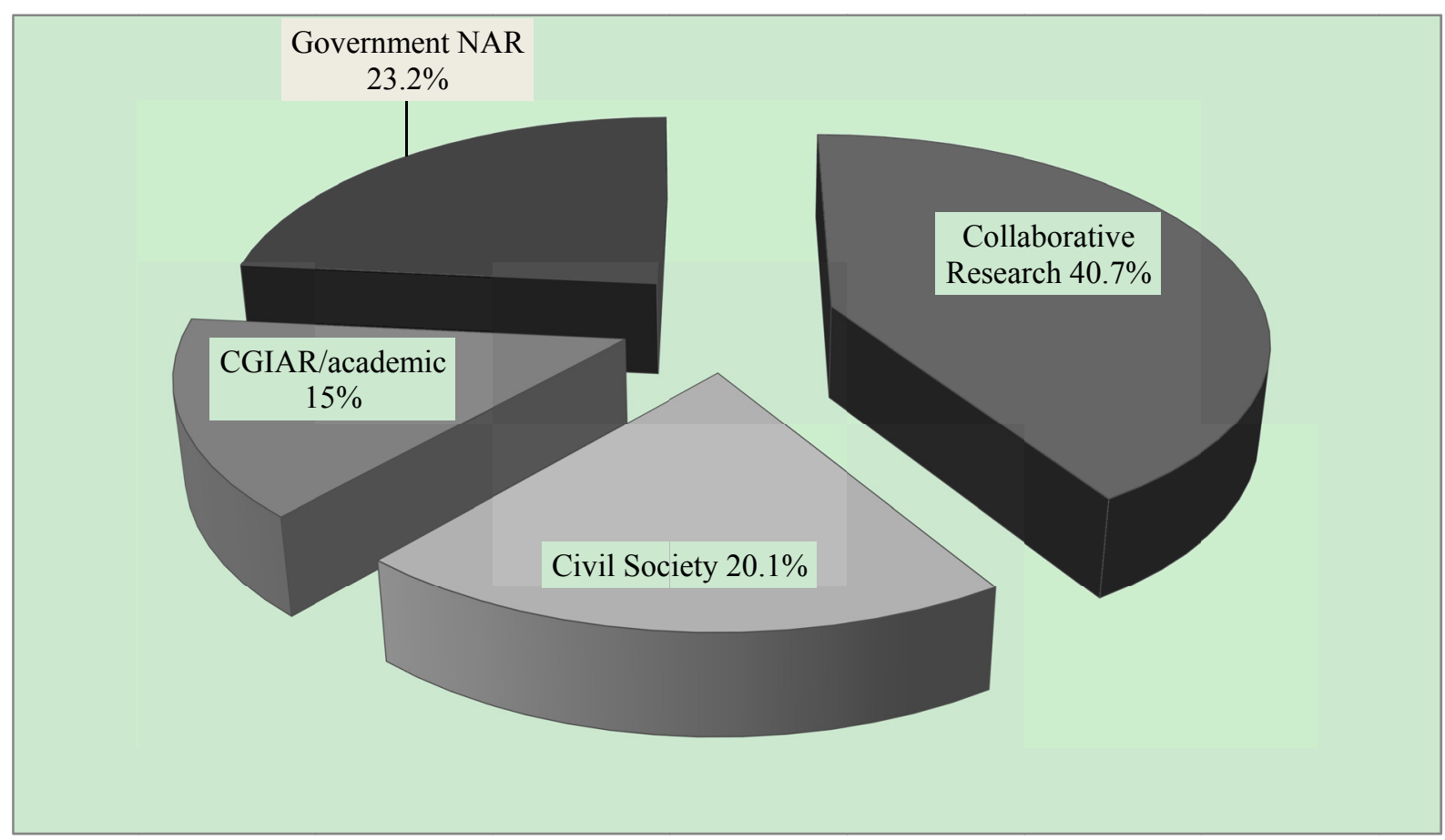

Figure 2. Uptake of agricultural research for agricultural policy and practice

Donor partners have strong influence as they work with civil society to influence policy formulation and implementation due to strong financial and political power. For the study, two civil society organisations stand out in Malawi and these are Civil Society Agriculture Network (CISANET) and Malawi Economic Justice Network (MEJN) have both successfully influenced through advocacy on farm input subsidy programme, climate smart agriculture, seed policy, biotechnology and food security among others. The strong network between Civil society organisations, donor partners has strong influence on research, policy and practice such that most research institutions including Consultative Group of International Agricultural Research Centres and the academia are collaborating with civil society organizations to engage government in a more effective way to influence policy and practice. These findings are also corroborated by work by Young (2005). These results agree with findings of Dehkordy, Shakhsian, Nawaser, Vesal \& Kamel (2013)who described donor partners as kingmakers at the top of the pyramid with necessary information and financial resources for influencing required policies which may not be in the interest of the public. On the other hand, the format of dissemination of research outputs was found to be one of the major contributing factors to policy and practice. Most research results from the academic circles either go to donors who commissioned them or they are published in international academic journals, which are difficult to understand and to be used by policy makers. Apart from research outputs provided as data and findings, other research outputs provided as briefs and arguments for actions have $60 \%$ chance of going into policy while agricultural research outcomes provided as ideas and criticism goes into policy gradually and has only $17 \%$ chance of being included.

As a case study, we assessed the extent agricultural research informs the farm input subsidy programme. Interviews with stakeholders from NGOs fertilizer and hybrid seeds, donor partners, and agricultural research centres show the existence of heated debate over the farm input subsidy programme regarding its scope and scale fertilizer and hybrid seeds and the ability of the Malawi government to fund and sustain the initiative. Several policy recommendations for example: Aberman, Droppelmann, Schiffer, Birner \& Gaff (2012); Mapila, Yauney, Droppelmann, Thangata \& Mazunda (2014); and other findings have suggested that research by Department of Agricultural Research, civil society, CGIARs and donor community is key to influencing process of policy development and formulation. Apart from interaction of the three stakeholder organizations, the Ministry of Finance and Ministry of Economic Planning are equally very crucial in getting research results that lead to agricultural policy and practice. 


\subsection{Review of Agricultural Sector Policies}

Figure 3 was produced from 5-point Likert scale where 50\% of the policies shows mean score of lower than 3 suggesting that climate change issues are not prominent. From the figure most agricultural sector related policies do not mention climate change because were formulated when issues of climate change were not prominent.

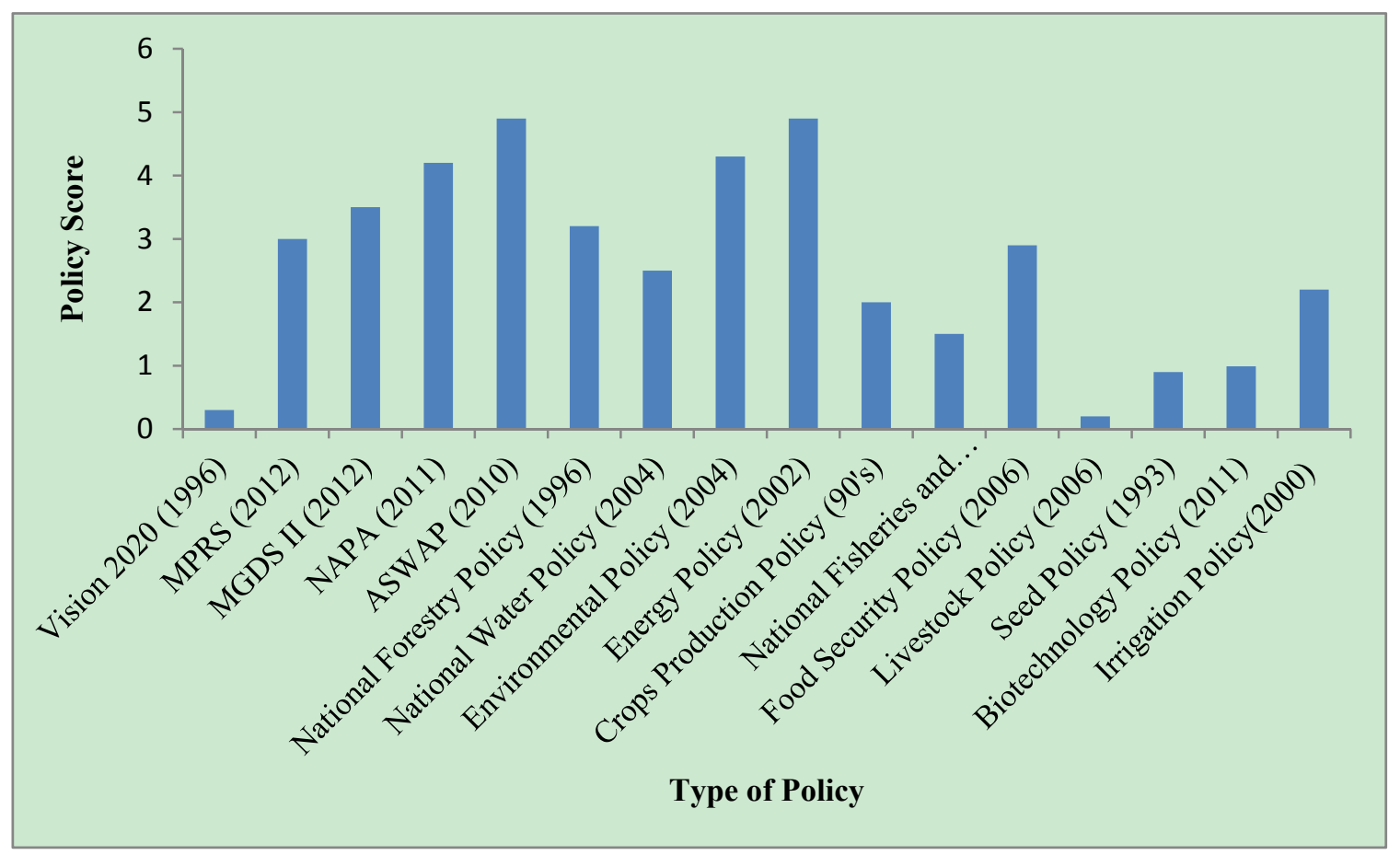

Figure 3. Extent of coverage of climate change issues in agricultural policies

Most of the agricultural related policies were formulated when issues of climate change were less topical and policy makers did not envisage that climate change will emerge as an issue that will receive significant global and national attention. Most of the policies did not adequately mainstream issues of climate change hence most of the strategies do not directly refer to climate change adaptation and mitigation (Figure 5). For instance, Vision 2020 formulated in 1996 stated that climate change would not have any significant impact on the livelihoods of people. However, since 2003, issues of climate change started gaining momentum such that Malawi realized the need to develop some strategies that would help in dealing with the climate change effects. This realization gave rise to the creation of the National Environment Policy of 2004 and National Adaptation Policy of Action (NAPA) 2005.The Energy Policy shows a great deal of mainstreaming climate change issues (Figure 3). Malawi has several agricultural development policies that should have articulated climate change issues but did not primarily because at the time of their development, climate change issues did not receive their present day priority attention.

\subsection{Linkage of Agricultural Practices, Research and Policy}

Several agricultural research studies and practices are being implemented in Malawi to improve resilience of smallholder farmers to climate change and increase agricultural production. Over 40 organizations including different government departments, private sector, faith-based groups, and non-government organisations have responded positively to the effects of climate change by implementing research activities that address issues of climate change. However, there is no policy guideline to serve as a model to be copied by all stakeholders and there is high duplication of efforts by several stakeholders. The Malawi Government relies on institutional research funded by different organizations to inform agricultural practices because public expenditure on agricultural research and extension is currently low (Government of Malawi, 2011b).

There is no single institution in Malawi that is specifically mandated to conduct climate change research. However, the National Commission for Science and Technology (NCST) is involved in coordinating research activities in Malawi. However, in most cases, research activities related to climate change are conducted by Department of Agricultural Research Services, and Department of Climate Change and Meteorological Services. 
Since the agricultural sector is highly vulnerable to climate change, some research on climate change-related topics have been conducted, including: crop response and performance under drought and soil-water stressed conditions as well as breeding crop varieties that are tolerant to drought and adapt to water conservation practices to control soil erosion.

\subsection{Agricultural Practices by Stakeholders and Farmers}

Communities rely on both conventional and indigenous methods of forecasting weather changes, for example $41.3 \%$ indicated that less and erratic rains were major signs for drought while $16.3 \%$ of respondents rely on the emergence of heavy southerly storm ( $m$ wera) winds as a signal for drought. Other indicators of drought are mainly phenological appearance of plants, while late flowering of trees as indicated by $22 \%$ of the respondents is used as an indication of impending dry spells. Higher fruit production by wild trees of nyenze and nkolobwe is a signal of looming drought in the season. These results agree with findings of Chang'a, Yanda, \&Ngana (2010) who reported that heavy flowering of Brachystegia spiciformis sand Erythrina abyssinica as an indication of well distributed rainfall which may be followed by floods. The results corroborate the findings of Magombo, Kanthithi, Phiri, Kachulu\& Kabuli (2012) who reported that local communities in Chikhwawa rely mostly on indigenous knowledge in forecasting weather.

The common adaptation practices adopted by communities include planting of trees and grass along river banks. Other practices include irrigation farming, relocation to upland areas, construction of embankments, crop diversification, and practicing of conservation agriculture (Figure 4).

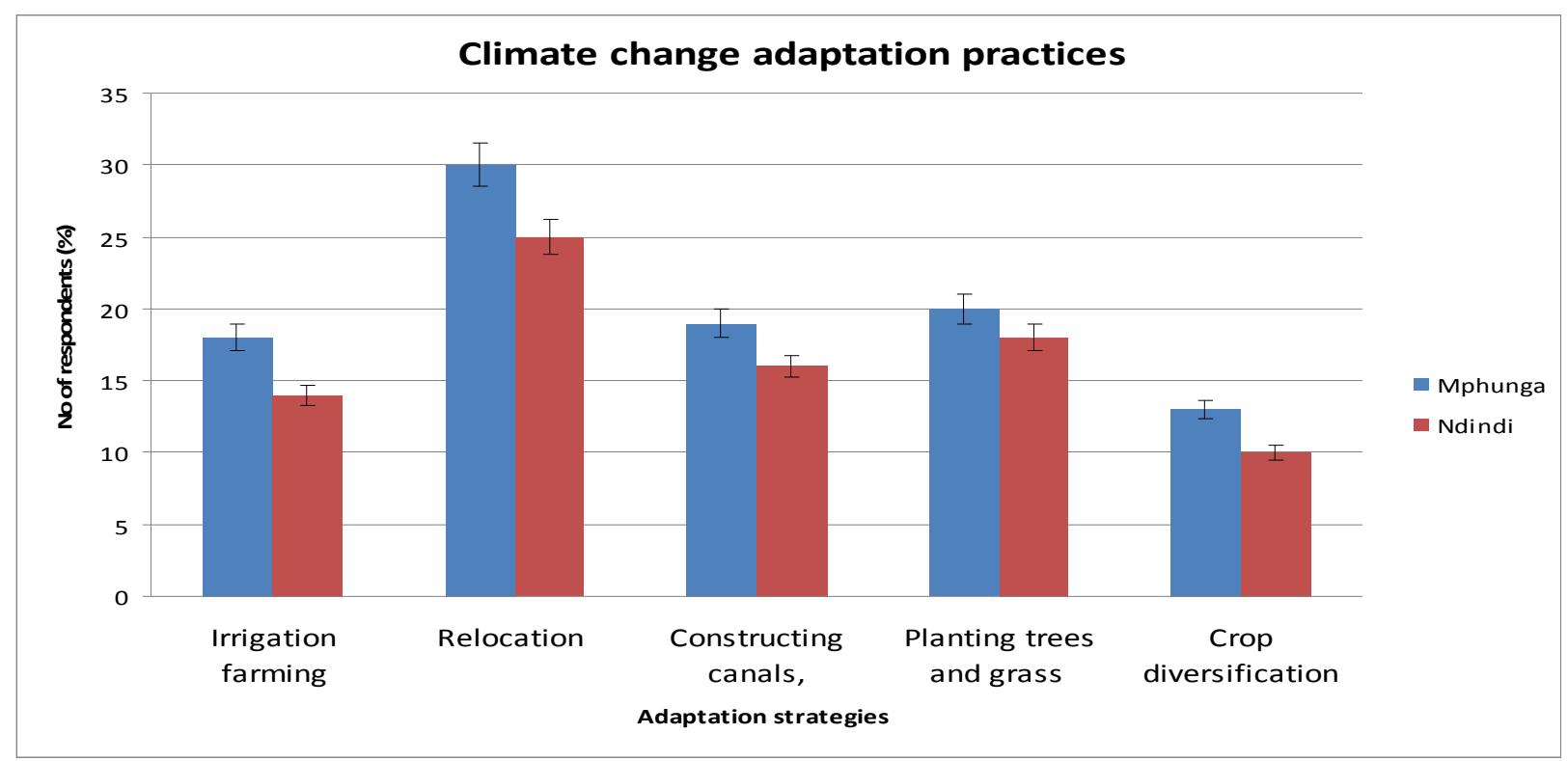

Figure 4. Agricultural practice as adaptation strategies to climate change in two villages in Malawi

The Department of Agricultural Research has critical mass of capacity to deal with climate change issues and develop technologies that will mitigate climate change impacts, but there is a $38 \%$ vacancy rate that is affecting its ability to develop technologies in line with demand. Government departments are relying on support by international agricultural and environmental organizations such as Food and Agriculture Organization, World Agroforestry Centre, World Bank, Department for International Development, Unites States Agency for International Development support research work in climate smart agriculture technologies. It is estimated that only $13 \%$ of farmers get advice from an agricultural advisers on crop and input management because of inadequate extension staff (Government of Malawi, 2011b; Chirwa, Kumwenda, Jumbe, Chilonda \& Minde, 2008).

Agricultural practice in the private sector is well supported and follows a good extension network. For example, the seed sector has over time adjusted to the changing needs of the farmer in response to climate change. Extensive research in high yielding crop varieties, early maturing, drought tolerant and disease resistant crops have been conducted resulting in the release of new seed varieties with these favourable traits. Focus group discussions with members of the two communities provided a long list of agricultural practices for climate 
change namely conservation agriculture, irrigation farming, manure making, rain water harvesting, agroforestry. Regarding the procedure through which the technologies were introduced, respondents indicated that the first step is to sensitize communities and mount demonstration plots for observation where farmers would then adopt the technologies and implement them on their farm lands. The extent of technologies is seen to be informed by research promoted by government departments. However, as a government policy, most practices have to be demonstrated through research. Thus, most technologies are first subjected to the Technology Release Committee in the Department of Agricultural Research Services for evaluation before being released for adoption by the farmers. This therefore necessitates research and multi-location trials to evaluate the practices. This clearly shows that most of the agricultural practices are emanating from research and are informed by different policies in the agricultural sector.

\section{Conclusion}

Overall, there are inadequate and ineffective strategies, systems and programmes for adapting to and mitigating against climate change, especially with regards to agricultural development and food security. Strategies to address climate change issues are scattered in different policy documents and there is no proper coordination of implementation of the programmes by several government departments, civil society, and non-governmental organisations. There is an inherent weak link between researchers and policy makers such that unless there is active lobbying that involves mostly donor partners and civil society working together with Department of Agricultural Research Services, important research work may not inform agricultural policy and practice. Agricultural practices among farmers are greatly influenced by the type of organization promoting the specific agricultural practice, the incentives provided, and payback period of the agricultural project among others. There is limited linkage between research, innovation and application of practices. Most research activities are donor driven which raises questions on sustainability of evidence based research work after donor support ceases. It is envisaged that the draft Climate Change Policy of Malawi will harmonize the agricultural sector policies with any policies dealing with climate change for effective implementation of strategies. There is urgent need for government to mainstream issues of climate change adaptation and mitigation into agricultural sector policies that would be informed by current research that takes into account the interests and challenges of farmers. The best practices emanating from efforts of research institutions should be integrated into agricultural practices by using agricultural extension services to develop and disseminate messages to implement best practices that enhance agricultural productivity. Stakeholders in the Ministry of Agriculture including the national agricultural research systems, CGIAR institutions, academic institutions, and donor partners should strengthen their links and cooperation to undertake quality research that should inform policy and practice. There is strong need to review some of the policies to include issues on climate change. Alternatively, the climate change policy under development in Malawi should cover strategies that focus on adaptation to and mitigation of climate change effects on agricultural practices and production given that the agricultural sector is highly susceptible and vulnerable to climate change.

\section{Acknowledgements}

The authors acknowledge the financial support by United Nations Economic Commission for Africa through the African Climate Policy Centre. Special recognition should go to staff of different government departments and Non Governmental organizations in Malawi for providing information during field interviews. The Director for Centre for Environmental Policy and Advocacy Mr William Chadza is acknowledged for mobilizing stakeholders in Southern Malawi for key informant interviews.

\section{References}

Aberman, N.L, Johnson, M., Droppelmann, K., Schiffer, E., Birner, R., \& Gaff, P. (2012).Mapping the Contemporary Fertilizer Policy Landscape in Malawi. IFPRI. Development Strategy.

African Development Bank.(2013). Malawi Country Strategy paper 2013 to 2017.

Chang'a, L.B., Yanda, P.Z., \&Ngana, J. (2010). Indigenous knowledge in seasonal rainfall prediction in Tanzania: A case of South-western Highland of Tanzania. Journal of Geography and Regional Planning, 3(4), 66-72.

Chirwa, W., Kumwenda I., Jumbe C., Chilonda, P.,\&Minde, I. (2008).Agricultural Growth and Poverty Reduction in Malawi: Past Performance and Recent Trends.ReSAKSS Working Paper No.8.

Court, J. (2005). Bridging Research and policy on HIV /AIDS in developing countries.ODI Working Papers. Overseas Development Institute: London.

Dehkordy, L.F., Shakhsian, F., Nawaser, K., Vesal, S.M., \&Kamel, A. (2013). Identification of factors Influential in Policy Making and Presenting a Combined Model of Iran's Policy Making.Journal of Sustainable 
Development, 6(8), 118-129. http://dx.doi.org/10.5539/jsd.v6n8p118

Government of Malawi (GoM). (2011a). Annual Economic Report 2011, Ministry of Development Planning and Cooperation.

Government of Malawi (GoM). (2011b). Malawi Growth and Development Strategy II: 2011 - 2016. Lilongwe, Malawi: Ministry of Development Planning and Cooperation.

Government of Malawi. (2010). Ministry of Agriculture and Food Security, the Agriculture Sector Wide Approach (ASWAp), Malawi's prioritized and harmonized Agricultural Development Agenda: 2011 to 2015. Lilongwe.

Magombo, T., Kanthithi, G.,Phiri, G.,Kachulu M., \& Kabuli, H. (2012).Incidence of Indigenous, Emerging and Innovative Climate Change adaptation Practices in Chikhwawa District, Southern Malawi. African Technology Policy Studies Network, Nairobi, Kenya.

Mapila, M.A.T., Yauney, J., Droppelmann, K., Thangata, P.,\&Mazunda. (2014). Who talks to whom in African Agricultural Research Information Networks? The Malawi Case. Journal of Agricultural Education and Extension, 1-7. http://dx.doi.org/10.1080/1389224X.2014.971827.

Young, J. (2005). Research, policy and Practice: Why Developing counties are different. Journal of International Development, 17, 727-734. http://dx.doi.10.1002/jid

\section{Copyrights}

Copyright for this article is retained by the author(s), with first publication rights granted to the journal.

This is an open-access article distributed under the terms and conditions of the Creative Commons Attribution license (http://creativecommons.org/licenses/by/3.0/). 